\title{
Capsule Commentary on Sullivan et al., Primary Care Opioid Taper Plans Are Associated with Sustained Opioid Dose Reduction
}

\author{
Jessica A. Chen ${ }^{1,2}$ \\ 'Health Services Research \& Development (HSR\&D) Center of Innovation for Veteran-Centered and Value-Driven Care, Veterans Affairs (VA) \\ Puget Sound Health Care System, Seattle, WA, USA; ${ }^{2}$ Department of Psychiatry \& Behavioral Sciences, University of Washington, Seattle, WA, USA.
}

$\mathrm{J}$ Gen Intern Med 35(3):980

DOI: $10.1007 / \mathrm{s} 11606-019-05520-7$

(c) Society of General Internal Medicine 2019

I $\mathrm{t}$ is a clinical and public policy challenge to balance opioid safety with effective and compassionate pain care, particularly among the five to eight million Americans currently taking opioids for chronic pain. ${ }^{1}$ Sullivan and colleagues ${ }^{2}$ present a rigorous nested case control study among Kaiser Permanente Washington enrollees on higher-dose, long-term opioids. They provide compelling evidence that a documented taper plan is associated with a four-fold increase of sustained opioid dose reduction, even after matching on opioid dose and for patients with documented opioid use disorder. SNRI/TCA antidepressants, gabapentin/pregabalin, and having at least one behavioral health visit were also associated with higher likelihood of sustained taper. Their findings support existing clinical practice guideline recommendations that, when the risks of opioid therapy outweigh the benefits, providers should work collaboratively with patients on planned tapers and offer non-opioid pain treatment alternatives.

However, a key issue in the current debate is not whether opioid dose reduction is possible, but rather, how conversations and negotiations about tapering negatively impact providers and patients. ${ }^{3}$ Electronic health record (EHR) data provide little information on the quality of patient-provider communication and cannot speak to whether these tapers were collaborative or forced. Notably, even among the 894 cases with a sustained taper, only $26.6 \%$ had a documented plan. This raises the question of whether most tapers were in fact unplanned or, at the very least, not documented in the EHR. The study also lacked data on how patients fared following sustained opioid taper.
As the authors note, primary care providers are the frontline for opioid safety. Amidst media reports of patient abandonment and denial of care due to providers' unwillingness to take on opioid prescriptions, there is an urgent need for guidance and evidence on how to effectively talk with patients about opioid safety and balance provider and patient concerns. More broadly, we must recognize that the opioid epidemic will not be solved through supply reduction alone. Substance use disorders $^{4}$ and social determinants of health ${ }^{5}$ are key drivers of the epidemic and must be addressed for healthcare system interventions or policies to be effective.

Corresponding Author: Jessica A. Chen, Department of Psychiatry \& Behavioral Sciences University of Washington, Seattle, WA, USA (e-mail: Jessica.Chen663@va.gov).

\section{REFERENCES}

1. Kroenke K, Alford DP, Argoff C, et al. Challenges with Implementing the Centers for Disease Control and Prevention Opioid Guideline: A Consensus Panel Report. Pain Medicine. 2019;20(4):724-735. https://doi.org/10. 1093/pm/pny307

2. Sullivan M, Boudreau D, Ichikawa L, Cronkite D, Albertson-Junkans L, Salgado G, VonKorff M, Carrell DS. Primary care opioid taper plans are associated with sustained opioid dose reduction. J Gen Intern Med.

3. Kertesz SG, Satel SL, DeMicco J, Dart RC, Alford DP. Opioid discontinuation as an institutional mandate: Questions and answers on why we wrote to the Centers for Disease Control and Prevention. Substance Abuse. July 2019:1-3. https://doi.org/10.1080/08897077.2019.1635973

4. Samet JH, Kertesz SG. Suggested Paths to Fixing the Opioid Crisis: Directions and Misdirections. JAMA Netw Open. 2018;1(2):e180218. https://doi.org/10.1001/jamanetworkopen.2018.0218

5. Dasgupta N, Beletsky L, Ciccarone D. Opioid Crisis: No Easy Fix to Its Social and Economic Determinants. Am J Public Health. 2018; 108(2):182186. https://doi.org/10.2105/AJPH.2017.304187

Publisher's note Springer Nature remains neutral with regard to jurisdictional claims in published maps and institutional affiliations. 